\title{
ЭКСПРЕСС-ОЦЕНКА ФАКТОРОВ ЦИФРОВОГО РАЗВИТИЯ ДЛЯ УПРАВЛЕНИЯ КОНКУРЕНТОСПОСОБНОСТЬЮ ПРОМЫШЛЕННЫХ ПРЕДПРИЯТИЙ
}

\author{
(C) 2021 Кулагина Наталья Александровна \\ доктор экономических наук, профессор, профессор кафедры «Государственное управление, \\ экономическая и информационная безопасность» \\ Брянский государственный инженерно-технологический университет, Россия, Брянск \\ E-mail: Kulaginana2013@yandex.ru
}

(c) 2021 Лысенко Александра Николаевна

кандидат экономических наук, доцент кафедры «Государственное управление, экономическая и информационная безопасность»

Брянский государственный инженерно-технологический университет, Россия, Брянск

E-mail: Sasha14-09@mail.ru

(c) 2021 Мугутдинов Рашид Магомедрасулович

аспирант Высшей инженерно-экономический школы

Санкт-Петербургский политехнический университет Петра Великого, Россия, Санкт-Петербург

Промышленное производство является основой для развития практически всех отраслей экономики, а темпы его роста определяют конкурентоспособность всех хозяйственных систем, независимо от уровня управления. На предприятиях промышленности создается большое количество инноваций, которые быстро распространяются и внедряются в повседневную жизнь человека, а также позволяют оптимизировать бизнес-процессы и наращивать конкурентные преимущества. Применение цифровых технологий в условиях промышленного производства приводит к существенным эффектам, а оценка уровня цифрового развития промышленного предприятия позволяет судить о динамике цифровизации и способствует правильности принятия управленческих решений в контексте совершенствования стратегического управления. Методологическая и практическая значимость выполненного исследования заключается в возможности использования предлагаемого инструментария для разработки стратегий цифровой трансформации предприятий промышленного сектора экономики.

Ключевые слова: конкурентоспособность, конкурентные преимущества, промышленное предприятие. цифровое развитие, циифровизация, цифровая трансформация.

В современных условиях процесс цифровизации, который является главным трендом развития всех отраслей народного хозяйства, преобразует структуру экономики, отношения между населением, государством и бизнесом, а также меняет жизнь общества. Степень цифрового развития определяется зрелостью материально-технической основы. Так как развитие промышленного производства в Российской Федерации имеет отставание от развитых стран, то цифровизация может стать одним из способов повышения показателей производства [7, C.11].

Цифровизация несет как положительные возможности, так и отрицательные моменты, которые необходимо учитывать в условиях оценки и управления конкурентоспособностью всех уровней хозяйственных систем. В свою очередь, темпы цифрового развития находятся в прямой зависимости с эффективностью деятельности как отдельного предприятия, так отраслей экономики в целом, а также является необходимым условием обеспечения темпов устойчивого роста.

Таким образом, процессы цифровой трансформации определяют современные тренды развития всех бизнес-субъектов и системы государственного управления, что требует своевременного и всестороннего их исследования, а их результативность выступает условием обеспечения конкурентных преимуществ бизнессубъектов, что подтверждает необходимость разработки четкого инструментария для оценки и мониторинга [8, С.36]. 
В настоящее время, авторами исследуются различные аспекты и отдельные стороны цифрового развития секторов, отраслей экономики, государств, регионов, предприятий и т.д. При этом отмечается, что процессы цифровизации в зависимости от вида экономической деятельности различаются между собой, следовательно, по-разному влияют на качественные параметры их конкурентоспособности [2, С.26], состояние интеллектуального капитала [3, С.132], уровень инновационного развития хозяйственных систем [9, С.3535].

Например, среди исследователей, предлагающих методические подходы к исследованию уровня цифровизации промышленных предприятий, следует отметить Бабкина А.В. и ПестовуА.Ю., которые предложили при 19 аналитических показателей, систематизированных на шесть основных групп: показатели цифровой инфраструктуры; показатели программного обеспечения; показатели материально-технического обеспечения; показатели трудовых ресурсов; финансовые показатели; организационно-управленческие показатели. Авторы считают, что предложенные показатели необходимо интегрировать в единую цифровую платформу предприятия и использовать как для мониторинга деятельности, так и оценки уровня его цифровизации, а также при формировании стратегии развития [1, С. 41].

Тимохина О.А., Близкий Р.С. предлагают авторский подход к оценке уровня цифровизации промышленных предприятий с использованием графоаналитического метода «Квадрат потенциала», которые также заслуживает внимание со стороны аналитиков промышленных предприятий [47, С. 51].

В тоже время, Ширинкина Е.В.для анализа цифровизации бизнес-субъектов предлагает использовать индекс цифровизации, на значение которого оказывают влияние такие показатели как использование таких цифровых технологий, как широкополосный Интернет, облачные сервисы, электронная торговля, RFID-технологии, ERP-технологии. Автор в своих исследованиях подтверждает зависимость уровня цифровизации предприятия от объема инвестиций в цифровые технологии, масштаба предприятия, количеством кадров с цифровыми компетенциями [5, С. 107].

Заслуживает внимания подход к исследованию процессов цифровизации промышлен- ных предприятий, предложенный Шендриковой О.О., Елфимова И. Ф. Основой авторского исследования являются показатели и методики оценки наиболее значимых свойств системы: эмерджентности, управляемости, устойчивости, адаптации, эффективности, чувствительности. Это дает возможность разработки средств воздействия на управляемость системы, а также обеспечивает возможность перехода к разработке задач оптимизации функционирования и развития предприятия как системы. Последующий анализ характеристик показателей выделенных свойств и выявление их взаимосвязей открывает перспективы для разработки способов и средств управления процессом цифровизации промышленных предприятий [6, С. 19].

Каждый из рассмотренных подходов имеет свою специфику практического применения, требует использования дополнительных источников информацию, которые в силу закрытости бизнес-субъектов не могут быть предоставлены заинтересованным пользователям, что влечет за собой определенные ограничения.

В процессе проведения исследования авторами было выявлено, что для расчета уровня цифрового развития промышленного предприятия необходимо рассчитать и проанализировать совокупность показателей, которые отражены в таблице 1.

Для оценки уровня цифрового развития промышленного предприятия необходимо учитывать наличие разработок предприятия с использованием передовых технологий, что свидетельствует об использовании современных технологий, в том числе информационных и цифровых.

Пользование электронными торговыми площадками говорит не только о прозрачности и открытости системы закупок, но и о компетентности персонала при работе с современными технологиями.

Применение технологий и систем отслеживания поставок позволяет без потерь времени и простоев наладить процесс производства продукции, спланировать деятельность предприятия.

Наличие электронных корпоративных систем способствует повышению качества управления производством, персоналом, финансами, а также комплексному планированию и развитию предприятия.

Чем выше на промышленном предприятии 
Таблица 1. Предлагаемая совокупность показателей для экспресс-оценки уровня цифрового развития промышленного предприятия

\begin{tabular}{|c|c|c|c|c|}
\hline № & Показатель & \begin{tabular}{|c|} 
Удельный вес \\
показателя, \%
\end{tabular} & $\begin{array}{l}\text { Обозначе- } \\
\text { ние }\end{array}$ & Способ расчета \\
\hline 1 & $\begin{array}{l}\text { Показатель наличия разработок пред- } \\
\text { приятия с использованием передовых } \\
\text { технологий }\end{array}$ & 10 & $\mathrm{~K}_{1}$ & $\begin{array}{l}\text { Если имеются, то балл составляет } 1, \\
\text { если отсутствует }-0 .\end{array}$ \\
\hline 2 & $\begin{array}{l}\text { Показатель пользования электронны- } \\
\text { ми торговыми площадками }\end{array}$ & 6 & $\mathrm{~K}_{2}$ & $\begin{array}{l}\text { Если имеются, то балл составляет } 1 \text {, } \\
\text { если отсутствует }-0 .\end{array}$ \\
\hline 3 & $\begin{array}{l}\text { Показатель применения технологий и } \\
\text { системы отслеживания поставок }\end{array}$ & 6 & $\mathrm{~K}_{3}$ & $\begin{array}{l}\text { Если имеются, то балл составляет } 1, \\
\text { если отсутствует }-0 .\end{array}$ \\
\hline 4 & $\begin{array}{l}\text { Показатель наличия электронной } \\
\text { корпоративной системы }\end{array}$ & 10 & $\mathrm{~K}_{4}$ & $\begin{array}{l}\text { Если имеются, то балл составляет } 1 \text {, } \\
\text { если отсутствует }-0 .\end{array}$ \\
\hline 5 & $\begin{array}{l}\text { Удельный вес персонала предприя- } \\
\text { тия, обладающего цифровыми компе- } \\
\text { тенциями }\end{array}$ & 10 & $\mathrm{~K}_{5}$ & $\begin{array}{l}\text { Отношение числа работников, } \\
\text { обладающих цифровыми компе- } \\
\text { тенциями, к общей численности } \\
\text { персонала }\end{array}$ \\
\hline 6 & $\begin{array}{l}\text { Показатель наличия электронного } \\
\text { документооборота }\end{array}$ & 6 & $\mathrm{~K}_{6}$ & $\begin{array}{l}\text { Если имеются, то балл составляет } 1 \text {, } \\
\text { если отсутствует }-0 .\end{array}$ \\
\hline 7 & $\begin{array}{l}\text { Показатель оснащенности рабочих } \\
\text { мест компьютерами }\end{array}$ & 9 & $\mathrm{~K}_{7}$ & $\begin{array}{l}\text { Отношение числа компьютеров к к } \\
\text { общей численности персонала }\end{array}$ \\
\hline 8 & $\begin{array}{l}\text { Показатель применения природосбе- } \\
\text { регающих технологий в деятельности }\end{array}$ & 9 & $\mathrm{~K}_{8}$ & $\begin{array}{l}\text { Если имеются, то балл составляет } 1 \text {, } \\
\text { если отсутствует }-0 .\end{array}$ \\
\hline 9 & $\begin{array}{l}\text { Показатель применение систем ин- } \\
\text { формационной безопасности пред- } \\
\text { приятия }\end{array}$ & 10 & $\mathrm{~K}_{9}$ & $\begin{array}{l}\text { Если имеются, то балл составляет } 1, \\
\text { если отсутствует }-0 .\end{array}$ \\
\hline 10 & $\begin{array}{l}\text { Показатель наличия автоматизиро- } \\
\text { ванной системы контроля качества } \\
\text { производимой продукции }\end{array}$ & 9 & $\mathrm{~K}_{10}$ & $\begin{array}{l}\text { Если имеются, то балл составляет } 1 \text {, } \\
\text { если отсутствует }-0 .\end{array}$ \\
\hline 11 & Показатель наличия сайта & 9 & $\mathrm{~K}_{11}$ & $\begin{array}{l}\text { Если имеются, то балл составляет } 1 \text {, } \\
\text { если отсутствует }-0 .\end{array}$ \\
\hline 12 & $\begin{array}{l}\text { Показатель применения электрон- } \\
\text { ных программ в управлении кадра- } \\
\text { ми (электронные трудовые книжки, } \\
\text { полисы ОМС и т.д.) }\end{array}$ & 6 & $\mathrm{~K}_{11}$ & $\begin{array}{l}\text { Если имеются, то балл составляет } 1, \\
\text { если частично присутствует }-0,5 ; \\
\text { если отсутствует }-0 .\end{array}$ \\
\hline
\end{tabular}

доля сотрудников, обладающих цифровыми компетенциями, тем быстрее происходит процесс его цифрового развития, переход от этапа цифровизации к этапу цифровой экономики.

Наличие электронного документооборота значительно позволяет автоматизировать данную деятельность, а также сократить затраты на нее.

Оснащенность рабочих мест компьютерами также является основой для перехода на цифровой путь развития.

Применение природосберегающих технологий отражает экологическую политику предприятия и призвано снизить степень негативного влияния от цифровизации на уровне промышленного предприятия.

В процессе цифрового развития возникает необходимость обеспечения информационной безопасности путем применения соответствующих средств защиты.
Применение цифровых технологий при производстве промышленной продукции не исключает контроля ее качества. Использование автоматизированной системы контроля качества позволяет существенного сократить затраты на данное мероприятие.

Наличие сайта предприятия является положительным моментом при осуществлении его деятельности, что позволяет расширить географию покупателей, увеличить доступность информации о предприятии и предлагаемой им продукции, повысить возможности свободного доступа к информации до 24 в сутки (на постоянной основе) и т.д.

Использование современных цифровых технологий и программ в управлении кадрами позволяет оптимизировать данную деятельность, что становится все более актуальными в условиях пандемии короновируса.

Источником информации для расчета уров- 
ня цифрового развития служат данные промышленного предприятия. При этом все показатели измеряются в диапазоне от 0 до 1.

Для определения удельного веса показателей, входящих в расчет уровня цифрового развития промышленного предприятия, используется экспертный метод. В роли экспертов выступили сотрудники отделов информационных технологий промышленных предприятий, численностью 52 человека.

Путем преобразований с учетом удельных весов, определенных экспертным методом, обобщенный показатель уровня цифрового развития промышленного предприятия будет иметь вид:

$$
\mathrm{I}=0,83\left(\mathrm{~K}_{1}+\mathrm{K}_{4}+\mathrm{K}_{5}+\mathrm{K}_{9}\right)+0,5\left(\mathrm{~K}_{2}+\mathrm{K}_{3}+\mathrm{K}_{6}+\mathrm{K}_{12}\right)
$$$$
+0,75\left(\mathrm{~K}_{7}+\mathrm{K}_{8}+\mathrm{K}_{10}+\mathrm{K}_{11}\right) \text {, }
$$

где I - обобщенный показатель уровня цифрового развития промышленного предприятия.

$\mathrm{K}_{\mathrm{i}}$ - значение показателей, входящих в расчет обобщенного индекса цифрового развития промышленного предприятия.

По результатам расчета обобщенного показателя уровня цифрового развития промышленного предприятия максимально возможное значение может составить 8,32.
Значения уровня цифрового развития промышленного предприятия заключается в следующих интервалах:

1. $[0 ; 2,08]-$ критический уровень цифрового развития промышленного предприятия;

2. $(2,08 ; 4,16]-$ низкий уровень цифрового развития промышленного предприятия;

3. $(4,16 ; 6,24]-$ средний уровень цифрового развития промышленного предприятия;

4. $(6,24 ; 8,32]$ - высокий уровень цифрового развития промышленного предприятия.

В случае наблюдения положительной динамики следует продолжать политику предприятия в области цифровизации. В противном случае необходимо проводить дополнительные мероприятия и принимать управленческие решения, которые будут способствовать повышению уровня цифрового развития.

Таким образом, практическое использование предлагаемого методического подхода позволяет провести экспресс-оценку уровня цифрового развития промышленного предприятия исходя из минимального набора характеристик, что выступает базисом для разработки комплекса мероприятий по управлению конкурентоспособностью промышленного предприятия.

\section{Библиографический список}

1. Бабкин А.В., Пестова А.Ю. Показатели для оценки уровня цифровизации промышленного предприятия // Актуальные проблемы развития хозяйствующих субъектов, территорий и систем регионального и муниципального управления. материалы XIV международной научно-практической конференции. 2019. C. 38-41.

2. Родионов Д.Г., Конников Е. А., Сергеев Д. А. Исследование механизмов взаимодействия субъектов цифровых экономических систем// Экономические науки. 2020. № 191. С. 25-31.

3. Родионов Д.Г., Конников Е.А., Алферьев Д.А. Информационный капитал предприятия как целевой показатель развития в рамках цифровых экономических систем//Экономические науки. 2020. № 190. С. 131 -137.

4. Тимохина О. А., Близкий Р. С. Оценка уровня цифровизации промышленных предприятий как одна из приоритетных задач в системе стратегического менеджмента современной организации // Менеджмент в России и за рубежом. 2020. № 5. С. 48-55.

5. Ширинкина Е.В. Оценка факторов и их значимости, влияющих на индекс цифровизации предприятий // Модели, системы, сети в экономике, технике, природе и обществе. 2020. № 2(34). С. 99-109.

6. Шендрикова О.О., Елфимова И. Ф. Исследование процессов цифровизации промышленных предприятий // Организатор производства. 2019. С. 16-24.

7. Харламов А.В., Харламова Т. Л. Трансформация российской хозяйственной системы: теоретические и практические аспекты// Известия Юго-Западного государственного университета. Серия: Экономика. Социология. Менеджмент. 2019. Т. 9. № 4 (33). С. 8-16.

8. Abeliansky A., Hilbert M. Digital technology and international trade: Is it the quantity of subscriptions or the quality of data speed that matters? // Telecommunications Policy. 2017. № 41 (1). P. 35-48.

9. Rodionov D., Rudskaia I. Problems of infrastructural development of «industry 4.0» in Russia on Sibur experience. В сборнике: Proceedings of the 32nd International Business Information Management Association Conference, IBIMA 2018 - Vision 2020: Sustainable Economic Development and Application of Innovation Management from Regional expansion to Global Growth. 32, Vision 2020: Sustainable Economic Development and Application of Innovation Management from Regional Expansion to Global Growth. 2018. C. 3534-3544. 